\title{
An unusually severe phenotype for familial adenomatous polyposis
}

D M Eccles, P W Lunt, Y Wallis, M Griffiths, B Sandhu, S McKay, D Morton, J Shea-Simonds, F Macdonald

Wessex Clinical Genetics Service, Southampton

D M Eccles

J Shea-Simonds

Clinical Genetics Service, Institute of Child Health, Royal Hospital for Sick Children, Bristol P W Lunt

DNA Laboratory, West Midlands Regional Genetics Service,

Birmingham

Heartlands Hospital

$\mathrm{Y}$ Wallis

S McKay

D Morton

F MacDonald

Child Health, Southampton General Hospital M Griffiths

Institute of Child Health, Royal Hospital for Sick Children, Bristol

B Sandhu

Correspondence to: Dr Diana M Eccles, Wessex Clinical Genetics Service, Princess Ann Hospital, Coxford Road Southampton SO16 6YA.

Accepted 8 July 1997
Abstract

Familial adenomatous polyposis (FAP) is a dominantly inherited predisposition to the development of many hundreds to thousands of adenomatous polyps of the colon. The mean age of onset is around 15 years, symptoms may arise in the third decade, and the median age for the development of colonic cancer is $35-40$ years. Prophylactic colectomy reduces the risk of death from colorectal cancer to such an extent that late sequelae such as upper gastrointestinal tumours have become the main cause of mortality in appropriately managed patients. The age at which colonic surveillance begins reflects the natural history of the disease. Onset of polyp formation and cancer in childhood is very unusual, but has recently been associated with a specific mutation at codon 1309 in exon 15 where a more severe phenotype is sometimes observed. The case histories of two families are reported in which there is childhood onset of polyps in the youngest generation and in one case a carcinoma, in whom mutations have been identified in exon 11 of the APC gene. Several other affected relatives were diagnosed at ages ranging from 5-48 years, some already with a cancer at the time of first screening. Since the aim of screening for colonic polyps is prevention of colonic cancer, family members at risk should be offered genetic assessment and direct mutation testing where this is possible, usually in the early teens. In the absence of a genetic test (the situation in about one third of families) or in a known gene carrier, annual colonoscopy examination is advised from the same age. Clinicians should take note of the family history and be prepared to consider much earlier intervention if symptoms occur in a child with a family history of FAP. Where childhood onset of polyps has occurred, other children at risk in the family must be offered earlier genetic testing and endoscopic surveillance. (Arch Dis Child 1997;77:431-435)

Keywords: familial adenomatous polyposis; polyposis; colon cancer

The gene for familial adenomatous polyposis (FAP) was localised in $1987,{ }^{1}$ and identified in $1991 .^{2}{ }^{3}$ Many of the identified mutations are unique to a single family but some commoner mutations have been found, accounting for about $10 \%$ of families. ${ }^{34}$ Since the cloning of the gene, correlations between the clinical features in family members and the site of the mutation within the gene have been sought. ${ }^{5-8}$ The presence of congenital hypertrophy of the retinal pigment epithelium correlates with mutations found $3^{\prime}$ of exon 9 and $5^{\prime}$ of codon 1444 in exon $15 .^{56}$ This feature, however, shows intrafamilial variability, and requires an experienced ophthalmological assessment to detect the more subtle lesions. Knowledge of the mutation site and the likely severity of polyposis may also influence choices on primary preventive surgery. ${ }^{9}$ A particularly severe form of polyposis with extra colonic manifestations, and early onset of polyposis, has been associated with mutations in exon 15 at codon $1309 .{ }^{10-13}$

We report two unrelated families where bowel symptoms and colonic adenomas have arisen in childhood; in each family there is a causative mutation in exon 11 of the APC gene. In both families there is an unusually early onset of multiple colonic polyps, congenital hypertrophy of the retinal pigment epithelium, osteomas, and sebaceous cysts, although desmoid disease has not been observed. The early age at onset in these families raises issues about genetic testing in childhood, bowel screening, and surgery, all of which may need to be brought forward by several years from the usual recommendations. ${ }^{14}$

\section{Materials and methods}

CLINICAL SAMPLES

Two unrelated families were separately identified through affected members who showed a classic picture of FAP diagnosed in the respective probands aged 7 and 15 years respectively. Both had the unusual feature of childhood onset of polyps in the younger generation. Venous blood samples from family members were collected and DNA extracted from peripheral blood leucocytes using standard procedures.

LINKAGE AND MUTATION ANALYSIS

Initially, linkage analysis was done using polymorphic markers flanking the APC gene (Pi227; C11p11; ECB27; YN5.48). Haplotypes were constructed using these four flanking markers allowing identification of the high risk haplotype. Subsequently, mutation analysis became possible and was initially done on one affected member of each family. This was done by polymerase chain reaction (PCR) 


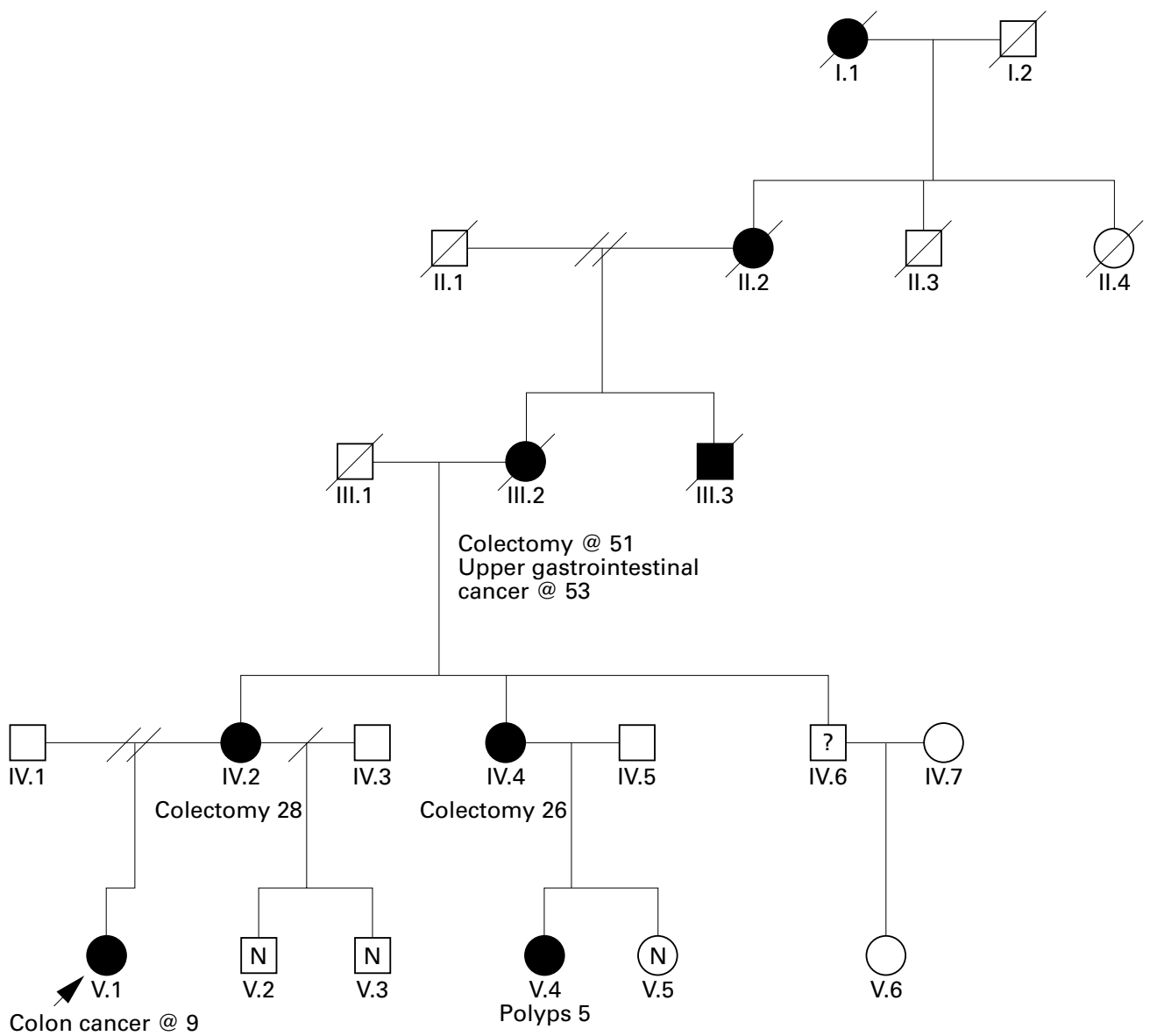

Colon cancer @ 9

Figure 1 Family 1.

amplification of each exon of the APC gene, or part of exon in the case of exon 15, and was followed with denaturing gel electrophoresis as previously described. ${ }^{7}$ Variant PCR products were sequenced on two separate occasions using a thermal cycle dideoxy DNA sequencing kit (New England Biolabs). ${ }^{7}$ After the mutation had been confirmed by sequencing, other family members at risk were tested by denaturing gel electrophoresis.

\section{Results}

FAMILY 1

The family member who brought the family to the attention of the genetics service was V.I in pedigree 1 (fig 1). She presented to the surgeons at the age of 3 years with a sebaceous cyst on her cheek. At 7 years of age she was investigated for a two year history of rectal bleeding. Sigmoidoscopy showed rectal polyps and subsequent colonoscopy showed many hundreds of small polyps throughout the colon. A biopsy specimen of some of the polyps confirmed these to be tubular adenomata with moderate dysplasia. She was followed up a year later again with colonoscopy at which time biopsy specimens were taken from further large polyps and one of these had the appearances of an early invasive carcinoma. She proceeded directly to a subtotal colectomy, and ileorectal anastomosis and histological examination confirmed the presence of a Dukes's stage A carcinoma. She was 9 years old at the diagnosis of her carcinoma and has remained well since then continuing with surveillance of the remaining rectal mucosa.

At the time of diagnosis of adenomatous polyposis in the child, a family history was taken which showed that her grandmother (III.2), great uncle (III.3), and great grandmother (II.2) had all had bowel cancers. The family was referred for genetic counselling, and the mother (IV.2), her brother (IV.6), and sister (IV.4) were referred on for colonoscopy examination.

Individual III. 2 presented initially at 51 years of age with several years of rectal bleeding, and was found at colonoscopy to have adenomatous polyps throughout the large bowel, some up to $2 \mathrm{~cm}$ in diameter. The diagnosis of FAP was made in her on the basis of the findings at endoscopy and confirmed in the resected colon specimen. The family were not offered screening at that stage in 1985, her youngest child was then 19 years of age. Two years later she was investigated for acute upper abdominal pain and jaundice and was found to have a carcinoma of the ampulla of Vater for which she had a pancreaticoduodenectomy. She died in the postoperative period of complications from this operation.

Individual IV.2 (age 27) admitted to intermittent rectal bleeding for several years on direct questioning in the genetics clinic. She was also noted to have several epidermoid cysts and asymptomatic mandibular osteomata. At 


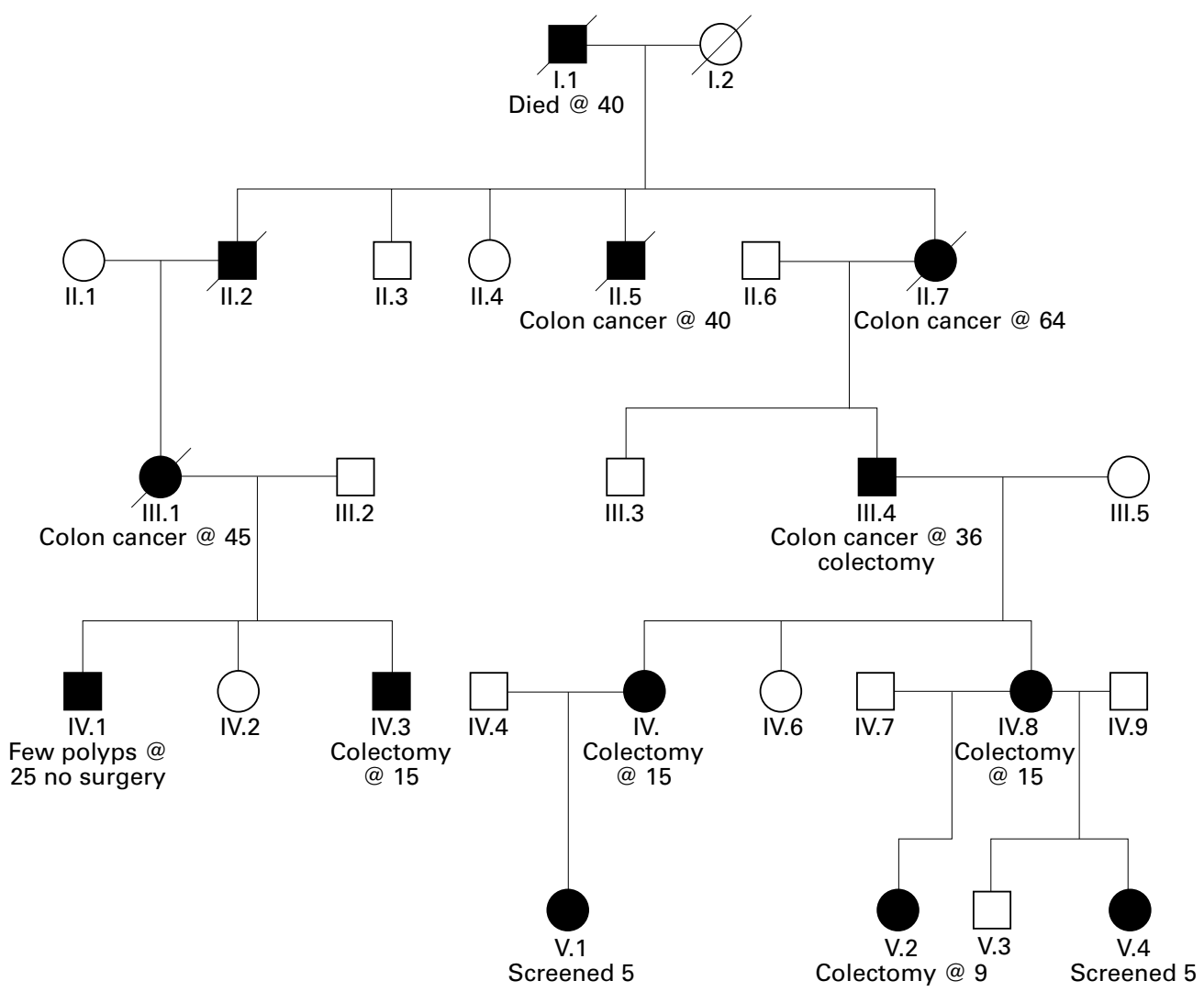

Figure 2 Family 2.

the time of her colonoscopy she was found to have thousands of adenomatous polyps throughout the colon, and histological examination of the subsequently resected colon showed that the polyps were most marked on the right side. Her sister, IV.4, who at age 29 similarly underwent bowel examination, was also found to also have florid colonic polyposis and she proceeded to total colectomy. Neither individual has developed cancer.

IV. 2 and V.1 have multiple pigmented retinal lesions (congenital hypertrophy of the retinal pigment epithelium) on ophthalmological review. Markers linked to the APC locus were used initially to assign high or low risks to other children in the family before bowel examination was offered. The results of linkage testing have subsequently been confirmed with mutation analysis.

FAMILY 2

This large family was referred initially to the genetics service because of the outcome of investigation of a 6 year old girl (V.2) after her mother was diagnosed with familial polyposis (fig 2). The daughter (V.2) was found on colonoscopy to have multiple small adenomatous polyps. There was minimal dysplasia and she continued under review until the age of 9 years when she had a colectomy. Nearly 100 polyps were present macroscopically in the specimen, none greater than $10 \mathrm{~mm}$ and none with more than mild dysplasia. The girl's mother (IV.8) developed rectal bleeding aged 10 years and had hundreds of polyps at the time of her first screen at 15 years. She under- went colectomy in her teens. The clinical course in IV.5 was very similar; the two sisters' other two daughters (V.4 and V.1) had colonoscopy at 5 and 7 years respectively and neither has yet developed histologically proved adenomatous polyps. V.1 had an irregular appearance to the rectal mucosa, but a biopsy specimen taken from it showed normal colonic mucosa. Both are known to carry the mutation shown in affected family members. Their grandfather III.4 had his first colonoscopy aged 36 years at which time hundreds of polyps were seen and at colectomy he had a Dukes's stage A carcinoma. His cousin (III.1) was first screened at 45 years and was found to have an invasive carcinoma from which she died a year later. In her two affected sons (IV.1 and IV.3), both of whom carry the mutation, the first screen was carried out at the time of their mother's diagnosis. The older son (IV.1) at the age of 25 years had very sparse polyps and is being managed conservatively. In contrast, his younger brother (IV.3) at the age of 13 years had already experienced rectal bleeding for a few years, had hundreds of polyps at colonoscopy, and proceeded directly to prophylactic colectomy.

\section{MUTATION ANALYSIS}

A variant pattern in exon 11 was identified by denaturing gradient gel electrophoresis in familes 1 and 2 . These variants were sequenced, and in family 1 was identified as a $\mathrm{C}$ to $\mathrm{T}$ transition at codon 499 . In family 2 , the mutation was identified as a $\mathrm{C}$ to $\mathrm{T}$ transition at codon 486. Both mutations lead to the 
immediate introduction of a stop codon and hence a predicted truncated protein product. In family 1 , this mutation was present in all affected members tested (IV.2, V.1, and V.4), but not present in V.5 and V.3 who were at risk. In family 2 , the mutation was also present in all affected family members (III.4, IV.1, IV.3, IV.5, IV.8, V.1, V.2, V.4), but absent from IV.2, IV.6, and V.3.

\section{Discussion}

FAP is caused by a mutation in the APC gene which is located on the long arm of chromosome 5 (5q21-22). Mutations are scattered throughout the gene. These two families show that onset of polyposis can rarely occur in childhood and this feature is not always associated with exon 15 mutations. Intrafamilial variability is also a recognised feature of FAP, and is observed particularly in these two families where screening in the youngest generation was initiated at a very early age.

Correlations between the site of the mutation in the very large APC gene and the clinical features in families may exist and can help in pinpointing a likely site of mutation, thus limiting the amount of time it takes to detect a causative mutation. For example, an attenuated form of the disease with a later onset and fewer polyps has been associated with a mutation in the first 4 exons, ${ }^{15}$ and with mutations at the $3^{\prime}$ end of the gene. ${ }^{16}{ }^{17}$ Other correlations are less certain but, for example, the presence of retinal pigmentary changes (congenital hypertrophy of the retinal pigment epithelium) observed in about $70 \%$ of patients and the presence of desmoid tumours (a relatively unusual feature) correlate with mutations in particular regions of the gene. ${ }^{51318}$ Recently, we have observed hereditary desmoid disease without polyposis associated with a $3^{\prime}$ APC mutation. ${ }^{19}$

Correlations between the clinical picture and the site of mutation may give some insight into the function of the protein product of the APC gene which is as yet uncertain. A number of specific domains, such as the region involved in binding APC to $\beta$ catenin (an increasingly important cell adhesion molecule), have been identified, which give some clues to possible function. ${ }^{20}{ }^{21}$ Other functional domains include the amino terminal region involved in oligodimerisation of the protein, ${ }^{22} 23$ and a carboxy terminal amino acid cluster involved in binding APC to the cytoskeleton. ${ }^{24}{ }^{25}$ Mutations interfering specifically with different functional domains may lead to differing clinical effects.

The correlation between mutation site and clinical features has given some clues to the structure and function of the APC gene product. Most mutations create an abnormally short protein product. Dimerisation of the protein occurs through the 5 ' end (front end) of the protein, this coupling can still occur with all but the most truncated of proteins. Binding of normal protein with truncated protein may reduce, or abolish, normal activity of those complexes. Short truncated proteins are unstable and cannot therefore form mutant/wild type dimers. This results in expression of nor- mal protein in the cells but at half the normal concentration (dosage effect). Patients with mutations at the 5' end of the gene therefore have a milder than normal phenotype. The more severe phenotype associated with the mutation at codon 1309 has been suggested to be due to the fact that the catenin binding domains are present in the truncated protein which may alter growth regulating signals. The mutations described in this paper lie within the heptad region of APC, and the truncated protein would lose the catenin binding domain. In these families, the phenotype is at least as severe as in patients with the 1309 mutation so there must be an alternative explanation related to the function of the gene to account for the severity in these two families.

In addition to the early onset, particularly in family 2 , there is marked intrafamilial variability in gene expression. This variability raises the possibility of human modifier genes. The presence of modifier gene(s) has been suggested in mouse models of FAP. ${ }^{26}{ }^{27}$ Assessment of polyp numbers can be somewhat subjective, especially when carried out in retrospect by different clinicians, and therefore the age at presentation with symptoms may be a better guide to disease severity. In family 1 , there is apparent anticipation with a much earlier age at onset of symptoms in the youngest generation. This has been observed in some other FAP kindreds, ${ }^{28}$ but it is still unclear whether this observation may at least in part be due to ascertainment bias. There are certainly inherited conditions where earlier age at onset in successive generations is very clear (for example, myotonic dystrophy), but for most of these the underlying genetic mechanism is somewhat different. In the formation of adenomatous polyps and colon cancer, however, there are a succession of acquired genetic hits and one might speculate about differing environmental agents to explain earlier ages at onset of polyps and cancers with successive generations.

In view of the well described natural history, most registers for managing the clinical follow up of individuals who are at risk of developing FAP recommend starting bowel examination from 12-15 years of age. ${ }^{29}$ The initial examination may be done by the paediatrician under general anaesthetic. Bowel examination is done annually until polyps become numerous, at which time prophylactic colectomy is planned. Often, if the responsible mutation in the family has been identified, family members can be offered a simple blood test before a colonoscopy. In those who do not carry the gene, this invasive test can thereby be avoided altogether. Without a gene test, those at $50 \%$ risk should be checked annually until they are at least 40 years of age because of the variation in the age at onset which can occur in this condition.

Genetic testing in children is usually avoided for adult onset conditions and is offered at a time when the individual can make his or her own informed choice. ${ }^{14}$ Testing children could potentially affect the way they are treated within the family. Where the testing will impact on the clinical management of a child, however, testing at a much younger age may be 
appropriate. In the families described above, two cases (V.4 in fig 1 and V.2 in fig 2) shown to have the gene had polyps at the time of their first screening aged 7 and 6 years. Histological assessment is essential, and colonoscopy is the investigation of choice. Barium enema is of limited value and repeated $x$ ray examinations in childhood and during reproductive years is not desirable. In view, in particular, of the cancer in one 9 year old patient we have recommended that bowel examination is carried out from 5 years of age in these two families. In this particular situation it is therefore appropriate to offer mutation analysis in the year before this. It is likely that there are specific sites in the APC gene more likely to be associated with a severe phenotype, we suggest that exon 11 is one such region in addition to the 1309 mutation in exon 15 .

In conclusion, all families with FAP should be assessed in a clinical genetics department. In many, a genetic test will be possible, thereby avoiding unnecessary and invasive investigations in children and young adults at risk of carrying the gene. Although in most families polyp formation starts in the second decade, there are a few families with FAP where the position of the mutation is correlated with an earlier onset of polyps and cancer predisposition. In most families with polyposis, colonoscopic surveillance should begin in gene carriers and those at 50\% risk (siblings and children of gene carriers) in the second decade commensurate with the age at onset of polyp growth. A careful family history is important in a symptomatic child and a family history of FAP should not be ignored, but should prompt investigation with the possibility of serious pathology a little more likely in this circumstance. Where polyps or cancers have occurred in childhood, early genetic testing and presymptomatic screening of at risk relatives is indicated.

1 Bodmer WF, Bailey CJ, Bodmer J, et al. Localisation of the gene for familial adenomatous polyposis on chromosome 5 . Nature 1987;328:614-9.

2 Kinzler KW, Nilbert MC, Su L, et al. Identification of FAP locus genes from chromosome 5q21. Science 1991;253: $661-4$

3 Groden J, Thliveris A, Samowitz W, et al. Identification and characterisation of the gene for familial adenomatous polycharacterisation of the gene
posis. Cell 1992;66:589-600.

4 Mandl M, Paffenholz R, Friedl W, et al. Frequency of common and novel inactivating APC mutations in 202 families with familial adenomatous polyposis. Hum Mol Genet 1994;3:181-4.

5 Caspari R, Olschwang S, Friedl W, et al. Familial adenomatous polyposis: desmoid tumours and lack of ophthalmic lesions (CHRPE) associated with APC mutations beyond codon 1444. Hum Mol Genet 1995;4:337-40.

6 Olschwang S, Tiret A, Laurent-Puig P, et al. Restriction of ocular fundus lesions to a specific subgroup of APC mutations in adenomatous polyposis coli patients. Cell 1993;75 959-68.
7 Wallis YL, Macdonald F, Hulten M, et al. Genotypephenotype correlation between position of constitutional APC gene mutation and CHRPE expression in familial adenomatous polyposis. Hum Genet 1994;94:543-8

8 Bunyan DJ, Shea-Simonds J, Reck AC, Finnis D, Eccles DM. Genotype-phenotype correlations of new causative APC gene mutations in patients with adenomatous polyposis. F Med Genet 1995;32:728-31.

9 Vasen HFA, van der Luijt RB, Slors JFM, et al. Molecular genetic tests as a guide to surgical management of familial adenomatous polyposis. Lancet 1996;348:433-5.

10 Caspari R, Friedl W, Mandl M, et al. Familial adenomatous polyposis: mutation at codon 1309 and early onset of colon cancer. Lancet 1994;343:629-32.

11 Nugent KP, Phillips RKS, Hodgson SV, et al. Phenotypic expression in familial adenomatous polyposis; partial prediction by mutation analysis. Gut 1994;35:1622-3.

12 Distante S, Nasioulas S, Somers GR, et al. Familial adenomatous polyposis in a 5 year old child: a clinical, pathologi$\mathrm{cal}$, and molecular genetic study. 7 Med Genet 1996;33:15760 .

13 Gayther SA, Wells D, Sen-Gupta S, et al. Regionally clustered APC mutations are associated with a severe phenotype and occur at a high frequency in new mutation cases of adenomatous polyposis coli. Hum Mol Genet 1994; 3:53-6.

14 Clarke A, Fielding D, Kerzin-Storrar L, et al. The genetic testing of children. F Med Genet 1994;31:785-97.

15 Spirio L, Olschwang S, Groden J, et al. Alleles of the APC gene: an attenuated form of familial polyposis. Cell 1993;75:951-7.

16 Scott RJ, Van der Luijt RB, Spycher M, et al. Novel germline APC gene mutation in a large familial adenomatous polyposis kindred displaying variable phenotypes. Gut 1995;36:731-6.

17 Van der Luijt RB, Meera Khan P, Vasen H, et al. Germ-line mutations in the 3' part of APC exon 15 do not result in mutations in the 3 part of APC exon 15 do not result in adenomatous polyposis. Hum Genet 1996;98:727-34

18 Miyaki M, Konishi M, Kikuchi-Yanoshita R, et al. Co-existence of somatic and germline mutations of APC gene in desmoid tumours from patients with familial adenomatous polyposis. Cancer Res 1993;53:5079-82.

19 Eccles DM, Van der Luijt RB, Breukel C, et al. Hereditary desmoid disease is a phenotypic variant of attenuated polyposis due to a 3' frameshift mutation at codon 1924 of the APC gene. Am f Hum Genet 1996;59:1193-201.

20 Rubinfeld B, Souza B, Albert I, et al. Association of the APC gene product with catenins. Science 1993;262:1731-4.

21 Su LK, Vogelstein B, Kinzler KW. Association of the APC tumour suppressor protein with catenins. Science 1993;262: 1734-7.

22 Su LK, Johnson KA, Smith KJ, et al. Association between wild type and mutant APC gene products. Cancer Res 1993;53:2728-31.

23 Joslyn G, Richardson DS, White R, Alber T. Dimer formation of the N-terminal coiled coil in the APC protein. Proc Natl Acad Sci USA 1993;90:11109-13.

24 Smith KJ, Levy DB, Maupin P, et al. Wild-type but not mutant APC associates with the microtubule cytoskeleton. Cancer Res 1994;54:3672-5.

25 Munemitsu S, Souza B, Muller O, Albert I, Rubinfeld B, Polakis P. The APC gene product associates with microtubules in vivo and promotes their assembly in vitro. Cancer Res 1994;54:3676-81.

26 Dietrich WF, Lander ES, Smith JS, et al. Genetic identification of Mom-1 a major modifier locus affecting Mininduced intestinal neoplasia in the mouse. Cell 1993;75: induced

27 MacPhee M, Chepenik KP, Liddell RA, Nelson KK, Siracusa LD, Buchberg AM. The secretory phospholipase A2 gene is a candidate for the Mom1 locus, a major modifier of ApcMin-induced intestinal neoplasia. Cell 1995;81: 957-66.

28 Presciuttini S, Varesco L, Sala P, et al. Age of onset of familial adenomatous polyposis: heterogeneity within families and among APC mutations. Ann Hum Genet 1994;58:33142 .

29 Burn J, Chapman P, Delhanty J, et al. The UK Northern Region genetic register for familial adenomatous polyposis coli: use of age at onset, congenital hypertrophy of the retinal pigment epithelium and DNA markers in risk calculations. F Med Genet 1991;28:289-96. 